\title{
Shape-shifting and pushing against the odds: staff perceptions of the experiences of first generation students in South Africa and the UK
}

\author{
Rachel Forsyth $^{1}$ (D) Claire Hamshire ${ }^{1} \cdot$ Danny Fontaine-Rainen $^{2} \cdot$ Leza Soldaat $^{3}$
}

Received: 22 November 2019 / Accepted: 16 February 2021 / Published online: 13 March 2021

(c) The Author(s) 2021

\begin{abstract}
The principles of diversity and inclusion are valued across the higher education sector, but the ways in which these principles are translated into pedagogic practice are not always evident. Students who are first in their family to attend university continue to report barriers to full participation in university life. They are more likely to leave their studies early, and to achieve lower grades in their final qualifications, than students whose families have previous experience of higher education. The purpose of this study was to explore whether a mismatch between staff perceptions and students' experiences might be a possible contributor to these disparities. The study explored and compared staff discourses about the experiences of first generation students at two universities, one in the United Kingdom (UK), and the other in South Africa (SA). One-to-one interviews were carried out with 40 staff members (20 at each institution) to explore their views about first generation students. The results showed that staff were well aware of challenges faced by first generation students; however, they were unsure of their roles in relation to shaping an inclusive environment, and tended not to consider how to use the assets that they believed first generation students bring with them to higher education. This paper explores these staff discourses; and considers proposals for challenging commonly-voiced assumptions about students and university life in a broader context of diversity and inclusive teaching practice.
\end{abstract}

Keywords First generation students $\cdot$ Staff perceptions of students $\cdot$ Widening participation · Inclusion

Rachel Forsyth

r.m.forsyth@mmu.ac.uk

Extended author information available on the last page of the article 


\section{Introduction}

Internationally, increased levels of participation in Higher Education (OECD 2018), mean that university entrants now represent a wide cross-section of the population in many countries. This increase has been positioned as a driver for the desirable outcome of social mobility in the UK (Milburn 2012) and for "good citizenship and for enriching and diversifying people's lives" in South Africa (National Planning Commission 2012, p. 317).

An increase in participation levels means that there are many more first generation students (those who are first in their families to go to university) in higher education. The terms 'first in family' or 'first generation' are contested at times; a widely-used definition is that the term refers to those whose parents and grandparents were historically excluded from higher education for reasons associated with racial, ethnic, socio-economic and/or linguistic diversity (Bell and Santamaría, 2018). A more nuanced approach acknowledges that "first generation students inhabit spaces where the intersection of race, class, and gender impact not only access to college but also their aspirations about their place in the unfamiliar land of higher education" (Jehangir 2010, p. 15). The notions of exclusion and place that this definition provides are important in considering student access and persistence in higher education.

As a group, first generation students have been extensively studied (Bell and Santamaría 2018; Spiegler and Bednarek 2013; O'Shea et al. 2017; Jehangir 2010). Despite an increase in their admissions to university, they are one of the student cohorts most likely to depart higher education early (Pascarella et al. 2004; Tinto 2006). Research in South Africa and the UK has highlighted that some students, especially those who are first generation, do not feel that they belong at university (Hamshire et al. 2012, 2013, 2017, 2018; Laubscher-Kelly et al. 2018). In addition to the challenges of inclusion and belonging for so-called 'non-traditional' students, there has been wide critique of the effectiveness of the higher education sector in terms of its ability to deliver social mobility (Archer et al. 2002; Hall 2012; Smit 2012). The overall picture is that first generation students may achieve admission to university without gaining full "epistemological access", (Morrow 2009, p. 77): that is, without having full access to the implicit expectations and hidden curricula needed to succeed in a university.

Providing admission to higher education is just the beginning of ensuring student success. In some studies, first generation students have reported feeling out of place at university (Leathwood and O'Connell 2003; Spiegler and Bednarek 2013) and many institutions have put additional support in place to facilitate students' learning transitions and the development of a sense of belonging at university. For example, in the UK, additional support for writing assignments, and peer mentoring opportunities might be offered (Thomas 2012). In South Africa, students are recommended a penalty-free opportunity to transfer onto an extended degree programme (EDP) that gives students more time to complete their degree and to adapt to the expectations and environment of the university. In addition, various resources, similar to those offered in the UK, are made available to 
students in order to bridge 'the gap' between secondary education and tertiary education. These services have generally been targeted at the perceived disadvantage of the students, and their apparent need to complete something additional in order to catch up with other students who enter university better matched to institutional expectations (O'Shea 2016). The notion of a 'deficit' and the provision of additional services to remedy a perceived lack for targeted groups of students with a focus on what the students lack can be problematic (Smit 2012; O'Shea et al. 2016; O'Shea 2015; Spiegler and Bednarek, 2013). Being identified as belonging to a particular demographic may lead to the student being stereotyped in a negative way (Devos 2003; O'Shea et al. 2016).

It is a reasonable generalisation to say that universities are still essentially liberal institutions, incorporating the principles of social justice and social inclusion (O'Shea et al. 2016; Bexley et al. 2013) and that the full inclusion of all students is an important goal in most, if not all, universities. Mbembe (2016, p. 30) has characterised the challenge of full inclusion as a need to achieve the "democratisation of access", suggesting that this is not merely about increasing the number of students from different backgrounds in universities, but about creating spaces where they have a genuine sense of belonging. The apparent persistence of challenges for first generation students internationally (Spiegler and Bednarek 2013) requires us to consider in what ways underlying institutional culture has remained resistant to change (Gair and Baglow 2018).

During the transition to university, academic staff are arguably the key point of contact for students, representing the aims and aspirations of the university, as well as being leaders in subject knowledge. They are expected to respond to the rapid changes in the student population, the shifting aims of curricula to meet twenty-first century expectations, and the burden of achieving research outputs and high positions in national and international rankings. All of this increases the pressure on academic staff (Bexley et al. 2013) and can make it difficult to challenge traditional teaching practices (Sanders-McDonagh and Davis 2018).

When academic staff have been asked about their approaches to teaching diverse groups of students, they generally show awareness of the challenges faced by those students (Leach 2011). Tanner and Allen (2007) suggest that academic staff can create more inclusive environments by being culturally competent. They define the term 'cultural competence' in relation to higher education as "... how effective a teacher is for those students who do not share the same personal characteristics or the same cultural background of that teacher" (Tanner and Allen 2007, p. 251). Whilst university teachers can have only direct experience of their own background, it is possible for them to have a realistic perception of the different backgrounds that their students come from. However, awareness alone may not lead to changes in practice. For example, Jawitz (2016) reported the challenges experienced by white academic staff in considering how to position themselves in support of black students in a South African context; adopting a change in approach may place them potentially in opposition to the ways in which their colleagues are working, which is an uncomfortable situation which may be difficult to sustain.

These previous studies reported staff reflections on their own practice in relation to students, but did not specifically ask about their perceptions of the experiences 
of first generation students. The study reported here was designed to explore what staff said about first generation students and consider whether their beliefs might be having an unintended effect on students' integration into university life, which might explain the slow pace of improvement in outcomes for first generation students.

\section{Methods}

Following our previous joint work exploring the experiences of first generation students, with an international team of researchers (see Bell and Santamaría 2018), the project team successfully applied for institutional funding to explore staff perceptions of students' experiences. Staff-student relationships are an important element of students' learning experiences and previous research had demonstrated that academic staff played a significant role in shaping the learning environment. We therefore wanted to explore the deeper nuances of staff perceptions of first generation students to discover how this aligned (or not) with the students' perceptions. The funding awarded provided an opportunity to interview staff in two quite different national and institutional contexts: an elite university in South Africa, and a modern university in the United Kingdom. There are many differences between these two contexts; the South African university is highly selective and attracts students from across the country and internationally. In the UK university, $51 \%$ of the students self-identify as first generation and around $70 \%$ come from within an hour's travel of the campus. We expected there to be considerable differences between the perceptions of staff in the two universities, which would be useful in comparing approaches to working with first generation students. We therefore chose a relatively large sample size of 20 participants in each institution.

Data were collected using a qualitative phenomenological design to explore the lived experiences of the staff, reflecting the aim to explore how the experiences of first generation students were perceived by staff. Data were collected using individual semi-structured interviews to explore staff perceptions, the robustness of these perceptions and origins of some of the perceptions of first generation students. The interview schedule was developed with reference to data that the team had previously collected on first generation students' perceptions of their experiences (Hamshire et al. 2018; Laubscher-Kelly et al. 2018), and was structured around four themes which aimed to explore staff understanding of first generation students' experiences: defining first generation students, perceptions of how first generation students experienced university life, perceptions of what support was available for students and perceptions of the needs of first generation students. Open-ended prompt questions for each of these four themes were agreed by the project team.

\section{Participants}

Convenience sampling was used to recruit 20 staff responsible for teaching or supporting learning in each institution, via internal emails which invited staff to participate. The participants represented a range of different disciplines; their job roles 
ranged from Professor to Student Support Tutor and the number of years they had worked in higher education ranged from one to 20 . The aim was to include a range of staff voices from across the academic environment to gain a more nuanced understanding of staff perceptions.

\section{Data collection}

The interviews lasted on average 40-50 min and they were audio recorded using a digital recorder to allow for both greater depth of analysis and addition of reflective notes. The audio files were transcribed verbatim, including para-linguistics, pauses and laughter. To ensure accuracy the transcripts were subsequently reviewed; any small discrepancies and omissions were identified and amended. Thematic analysis of the interview data was undertaken using a process similar to framework analysis (Ritchie and Spencer 2002; Spencer et al. 2013). Srivastrava and Thomson (2009) suggest that framework analysis is an appropriate approach to adopt when inductive (data driven) analysis is used alongside analysis based on a priori issues. A lineby-line analysis was undertaken and emerging themes noted using a constant comparative approach. Phases of familiarisation and indexing led to the development of a thematic framework, discussed and agreed between the authors. The transcripts were considered individually by teams in South Africa and the UK and then discussed until mutual consensus about the meaning of the data was reached between the two research teams.

\section{Ethical considerations}

This project was approved by ethics committees at both the Manchester Metropolitan University (Faculty of Health, Psychology and Social Care) and the University of Cape Town, Centre for Higher Education Development (CHED). Involvement in the project was voluntary and staff responded to an email invitation to participate followed by a period of two weeks to decide if they wanted to take part. An information sheet outlining the ethical considerations was given to all participants; once a time for an interview had been arranged, the staff were given an opportunity to ask questions before the interview began and written consent was given to the recording of the interviews.

\section{Findings}

The interviews were semi-structured, giving staff the opportunity to discuss their perceptions and expectations regarding first generation students. Staff are not routinely provided with data about numbers of first generation students in a cohort in either university, so their comments are based on impressions and assumptions, unless individual students had made an explicit declaration of their previous experiences. 
Thematic analysis of the data resulted in the development of two global themes; (1) Shaping an inclusive learning environment; and (2) Understanding what students bring with them. Despite the very different contexts of the two universities, the overall findings showed little difference in the perceptions of staff.

\section{Shaping an inclusive learning environment}

Across the data set, staff noted that first generation students had skills and experiences that should be celebrated but there was a tendency to focus on difficulties that were encountered as students transitioned to the higher education environment:

Almost like walking into an unknown jungle and you don't know what is being thrown at you. (SA staff).

They are waiting for somebody to pat them on the shoulder and say 'you don't belong here'. (UK staff).

However, despite an awareness of the multi-faceted nature of first generation students' experiences, staff perceptions of inclusive pedagogy and therefore the creation of an appropriate learning environment did not always demonstrate a sense of responsibility for student inclusion; as noted by staff at both institutions:

I think it's a good idea that there is a dialogue but I think it depends what is being done with that dialogue. (UK staff).

I think there needs to be more of a sense of community amongst first year students and I don't know how the university generates it. (SA staff).

A number of the interviewees also perceived that although policies were in place across their institutions to facilitate student inclusion, the actual enactment of these by all staff was not always apparent:

I think the university is not adaptable enough to really respond to who is in our universities, what they need, how they learn ... university needs to get woke, ${ }^{1}$ get all kinds of woke and we need to create spaces for younger people to have a voice in everything that we do. (SA staff).

I'm very much of the opinion that I think it's great that there's discussion about diversity and inclusivity and all that, but I think sometimes that can mask what is actually happening (UK staff).

A small number of staff noted that shaping an inclusive environment across an institution needed a commitment from staff to support students appropriately and value them as individuals although they did not identify their own responsibility in acting on this:

I see some of the approaches that some of my colleagues have with the students and it's very much the-Do you remember that old adage of we should teach the students we have and not the students we would like to have? And some... still want to teach the students they want rather than the students they've got. (UK staff).

It's about being creative and thoughtful and conscious of all these different diversities and challenges. It's incredibly complex, it is difficult and it's a mess ... and

\footnotetext{
1 'woke' is a colloquial term used to indicate a political consciousness of issues (sometimes used pejoratively).
} 
you work with it. (some colleagues) see themselves as superior, they can't relate to different students, they are arrogant, they have the idea that if you are at university then pull up your socks and just get on with it. (SA staff).

A significant focus of all of the interviews was the support needs of first generation students and how staff could embed support within the curriculum:

Speaking for myself but also speaking for many of my colleagues, it's kind of the reason why we're in this job, really - to what I would call widening participation and to enable these kinds of students to build their confidence and to find- to develop a voice. (UK staff).

We should be more aware of the whole student and not what you are teaching to them... the academic staff are concerned with what they are teaching but that isn't where it ends especially for someone who is completely new and in a foreign space.' (SA staff).

However, underneath this positivity was a discourse of deficit that tended to problematise the students:

It requires different approaches sometimes, and we've got to take account of that. Just the same way as you would take account for gender, ethnicity, disability. And in some respects ... being a first generation is akin to having a disability.... (UK staff).

I think, really, the problems I think they'll have is this sort of imposter syndrome and not really understanding how to navigate the whole, you know, complex university system and thinking that, well, maybe this place isn't for me or I'm not good enough. (UK staff).

Characteristic of the comments about the environment is a slight disconnection of the interviewees from what 'the university' is doing, as though the interviewees themselves are not directly connected to the challenges faced by students. Overall, whilst there was a clear commitment to enable students' learning, their comments frequently deferred to a grand narrative that presented stereotypical thinking.

\section{Understanding what students bring with them}

Implicit across all of the interviews was an understanding that whilst the students did not have a familial history of higher education to draw on they had other personal resources and experiences to bring with them. However, a deficit discourse that focussed on difference and perceptions of what the students lacked was evident as a nuanced undertone. Students were variously described as coming from "bleak", "low income" and "less strong educational ethos backgrounds" by the UK staff and the South African staff noted that first generation students were "those who have no clue what to do" and that "expectations are often completely unrealistic and illinformed". In addition, a number of South African staff also identified race as a factor "When we talk about first generation students, we are often talking about students of colour who come from lower than middle class families" (SA staff).

Some of the interview participants made quite general assumptions about students' previous experiences and this alienating academic discourse may in itself be limiting students' opportunities for development: 
Many of them have been through the comprehensive [school] system and many of them have been through schools that aren't so good. (UK staff).

What's their aspirations and hopes going to be if their parents are sitting at home watching daytime TV? (UK staff).

Students will experience an additional level of challenge or require additional support just because they are that much less familiar with practices that we value here' (SA staff).

Whilst there were overlapping narratives within all the interviews that both hailed the success of first generation students, and noted that "parents are usually really proud of the students" the staff also commented on what they considered to be problematic characteristics of first generation students such as their accents and confidence levels;

We do notice. We notice sometimes by their accent, by the way they- they aren't quite as professional in their outlook as some of our other students, but that's doing them a disservice because some of our other students are quite unprofessional as well. But you can just hear their accent and you kind of know because they'll pronounce words wrong. They'll not necessarily know how to function in, say, like, a training profession environment. (UK staff).

First generation students are more likely to drop out because when they struggle they don't, they don't have the confidence or they don't have the knowhow to negotiate the system sometimes. (UK staff).

In addition, staff repeatedly raised issues around how they perceived that family networks and cultural competency impacted on students. There was a conceptualisation of students' experiences being a linear process of becoming and that if their families had not been to university then they were essentially lacking some key elements of understanding:

Students who have lots of members of the family go to university before them, there is a discussion about this will happen, that will happen, you'll have this, you'll do that, this will be an issue, watch for this, don't do that. (UK staff).

There is an enormous pressure to succeed. It's no joke to be first in family, high hopes are pinned on you and enormous resources and investment are poured into you. (SA staff).

The concept of problematic transitions between family and home networks and the university setting was also identified as potentially burdensome by a number of the staff; particularly if this included a geographical relocation and dislocation from home:

So there's some kind of transitioning that I think that first generation people have to do, which is not just about learning in the academic sense; it's also about learning to adapt and hybridise themselves to kind of shape-shift in some ways so that they can be one thing when they come into university and with their university friends or whatever. But they also have to do some sort of transitioning and shape-shifting as they travel back out from that again. (UK staff).

Students were sometimes perceived as living between the spaces and cultural norms of home and university; which ultimately displaced their sense of self. Indeed, whilst 'home' is often perceived as providing familiarity and 
predictability for students, it was highlighted that for some returning to a place that had fixed perceptions of them could be daunting for students:

I imagine that it is hard when you get here and then you struggle, and you are barely coping and you go home and you are a hero. If you are failing then how do you go back home as the hero and tell your family and the community that. (SA staff).

Within this concept of troubling transitions staff also noted how 'shape-shifting' between the spaces of home and university could impacted on students' peer networks and lead to potential isolation from peer support, at a point when social engagement was essential for a successful transition:

I know from my students that I've taught in the past, it is very specific, caught in the middle, not quite being understood by the family but not quite being understood by the peers, it's that kind of caught between two cultures, which is a very specific position. (UK staff).

...there's a couple of students that come to mind who are first generation students who stand out, ... they have not managed to make friends, it's just they are just different to the others and so that's the reason why they have not managed to make friends. (UK staff).

I still find people sitting together in groups with people they are comfortable with, typically their friends and often it is based on race. (SA staff).

Overall, despite the positive perceptions of first generation students that were articulated by the staff, across the dataset, there was a tendency to generalise and make assumptions about students' previous experiences and to undervalue the skills and knowledge the students brought with them.

Despite the extensive differences in national and institutional contexts, there was a strong similarity in the views expressed by staff in the two institutions, and so our discussion considers all of the responses together.

\section{Discussion}

The staff who participated in this study gave generously of their time and showed uniform commitment to the inclusion of first generation students; in selecting comments to illustrate our themes, we do not intend to be critical of them or their efforts to provide the best support for their students.

Our participants were self-selected in response to a request to participate in research about first generation students. Some staff volunteered that they had themselves been first generation students; in a future study, we would ask this question systematically, as it may have influenced their views. Overall, they were positive about working with students and described how they valued the opportunity to support students in their transition to the higher education environment. However, analysis of the transcripts gave a very clear sense of a deficit discourse in relation to first generation students, which accords with reports from students who don't feel they fit in with an expected model. For example, working class students in the UK have talked about 'passing' as something they are not, or fitting in academically, but not socially (Gagnon 2018; Reay et al. 2010). 
A learning environment that is inclusive needs to facilitate a sense of belonging for students; and they need to feel that they have the right to be there (Kahu and Nelson 2018; Reay et al. 2010; Thomas 2012). First generation students are often problematised as the 'others' who need to change to fit in with the prevailing habitus (Burke 2008, 2012; O'Shea et al. 2016; Spiegler and Bednarek 2013). Students' experiences are diverse and complex, and a welcoming institutional culture needs to value this, and consider how the institution needs to change, rather than the individuals who share that institutional culture (Spiegler and Bednarek 2013).

A key finding of this study was the underlying assumption from our interviewees that first generation students come from a different and somehow less satisfactory environment, and that academic success may be contingent on students changing the way they behave, leaving behind their friends and families, and developing new identities. These perceived differences were often framed in negative ways, and the assumption of the staff in this study was that students needed to 'shape-shift' in order to fit in to the university community. This is in line with previous studies of first generation students which depict students as lacking the necessary capital to enact success (O'Shea 2015), and is particularly problematic as it depicts the students' problems as individual rather than structural (Spiegler and Bednarek 2013).

The over-arching discourse of 'independent learners' that is often used to characterise higher education students transfers responsibility onto students to be accountable, and the interviewees who participated in this study had a clear sense that first generation students were different, and that they generally needed additional support to be academically successful. The staff noted that their university may not have fully inclusive structures, but they did not entirely consider themselves to be implicated and tended to refer to 'the university' in the third person, particularly when pointing out difficulties such as 'complex' systems which were difficult for first generation students to navigate. We are not suggesting that this was the intention of our interviewees, rather that they tended be relatively uncritical of organisational structures and practices, whilst expecting students to adapt themselves with the support of supplementary programmes.

In order to facilitate change we therefore need to step back and consider the range of obstacles that first generation students encounter during their higher education journey. The political, ideological and historical influences on students' experiences have been described in depth (O'Shea et al. 2017) but the focus still remains on policies and processes rather than on how these can be enacted by staff. The question therefore remains on how university staff could capture more agency over change by considering their own sphere of influence in relation to creating an inclusive and welcoming learning environment rather than on positioning students as responsible for their own success and choices.

Students come to university for diverse reasons, but at least some of those reasons are connected to learning the rules of a different life to which they seek entry. Intellectual change should equip them to make their own decisions about what they value, how they speak, which newspapers they read and their future relationships with their home communities. To what extent are university staff directing these decisions with their tacit assumptions? How much should students be required to 'shape-shift' in order to gain admission to different cultures? If we are committed 
to a pedagogy of access, then how do we ensure that both our discourses and our practices are inclusive?

Whilst we acknowledge that students' educational trajectories are constrained and influenced by previous experiences we need to encourage academic staff to consider a wider range of approaches, recognising the skills that these students bring and consider how they can contribute to developing an inclusive university. Recent work on students' own perceptions of their achievements (O'Shea and Delahunty 2018; Picton et al. 2018) has shown that on a day-to-day basis they focus much more on their own behaviours than on academic success, although one might postulate that this will change as they continue through their courses. Focussing initially on the short-term integration of students into the university environment is likely to be important in helping them to feel that they are achieving academically, but there needs to be a fundamental shift in emphasis to acknowledge the capabilities students have and to 'fit' the institution to the students to ensure that they feel valued and welcomed. This will only be achieved if staff feel able to value differences and to provide an inclusive and welcoming learning community.

\section{Conclusion and implications}

This paper has presented views about first generation students expressed by a selfselected group of staff working in two quite different universities. The authors are well aware of the complex differences between the UK and SA educational and social contexts, and further exploration will consider this in more detail. However, it was striking that in both institutions, staff expressed a strong commitment to diversity, but felt unsure about how to influence structural change which would bring about genuine inclusion.

Although universities may feel like bastions of tradition, 'being' a university is always unfinished business; institutions are constantly in the process of adapting in response to changing policy and politics, both local and global (Barnett 2010). 'Being a university' is an on-going process of 'becoming' as universities are constantly developing, and therefore there is no reason for universities to teach or relate to students in the same way for ever. A willingness to adapt to a changing student demographic is apparent from the provision of additional services for first generation students.

We would like to propose some ways in which the deficit discourse could be overturned by some changes in perception and policy in universities. In this study, staff tended to perceive the challenge to students as one of needing to fit in with a conventional university education; the possibility of a change in culture or approach was never volunteered by our interviewees. Staff were aware of a range of resources and services available to support students who were not able to fit in straight away, but the support was always provided somewhere else in the university. The staff who were interviewed had a strong sense of commitment to the success of first generation students; but seemed unable to visualise their own place in actions to make it happen. Some of our interviewees talked with admiration about the challenges their students had overcome in order to gain entrance to 
university, to persist with their studies after gaining 'formal' access, and to keep on coming in when circumstances made living and travelling very difficult. In this narrative, first generation students are portrayed as heroes who overcome the odds to integrate. The agency is all with the student and the support, rather than being shared across all members of the university community.

There is no doubt that some teachers are clearly already exercising their own agency to provide inclusive learning experiences which value what students bring with them, but the data presented here demonstrate that a substantial cultural change may be needed to bring about true institutional inclusion. An educational development approach to this might be to actively support staff in creating new narratives for their expectations of students, and visualising alternative ways of structuring curriculum and assessment. Perhaps some of the extraordinary resilience staff reported in their first generation students could be harnessed and valued in academic problem-solving? Could we consider ways to allow students to express themselves outside a narrow set of academic rules about language and assignment structure? One major recommendation of the UK-based 'What Works' project for student retention and success was to include "group-based learning and teaching that allows students to interact with each other, share their own experiences and learn by doing" (Thomas 2012, p. 31). Orientation and induction activities could embed this in any disciplinary area, contributing to students' development of key analytical and problem-solving skills, without privileging previous academic knowledge.

There are other measures which could be taken to put more emphasis on tutor agency in developing the learning community, rather than putting all of the responsibility onto 'the university' to provide specialist support. For example, when course curricula and structures are reviewed, specific questions could be asked about how the course has been designed to make sure that it is fully accessible, and that the course team have considered what students bring with them which will contribute positively to the university and the course. Students could be recruited from diverse backgrounds to have paid roles to work in partnership with staff to consider the impacts of different teaching and assessment approaches, and also to mentor fellow students as they integrate into university life. In these ways, gradual changes to attitudes may occur which result in a stronger sense of community and belonging for both students and staff.

Many positive changes are already happening in universities, but there are many challenges for the individual teacher to bring about genuine transformation in a traditional university framework. Making changes to conventional assessments and teaching techniques requires a great deal of individual confidence or a structured framework provided by the university. Teachers need permission to do things differently. In some cases they will feel supported in doing this by their own approaches to diversity (Leach 2011), but changes in institutional approach will give a much broader freedom to innovate around inclusion, and may help to reduce the discourse of deficit and an increased perception of the value brought to universities by first generation students. 
Open Access This article is licensed under a Creative Commons Attribution 4.0 International License, which permits use, sharing, adaptation, distribution and reproduction in any medium or format, as long as you give appropriate credit to the original author(s) and the source, provide a link to the Creative Commons licence, and indicate if changes were made. The images or other third party material in this article are included in the article's Creative Commons licence, unless indicated otherwise in a credit line to the material. If material is not included in the article's Creative Commons licence and your intended use is not permitted by statutory regulation or exceeds the permitted use, you will need to obtain permission directly from the copyright holder. To view a copy of this licence, visit http://creativecommons.org/licen ses/by/4.0/.

\section{References}

Archer, L., Hutchings, M., Leathwood, C., \& Ross, A. (2002). Widening participation in higher education (pp. 193-202). Issues of exclusion and inclusion.

Barnett, R. (2010). Being a university. Routledge.

Bell, A., and Santamaría, L. J. (2018). Understanding experiences of first generation university students: Culturally responsive and sustaining methodologies. Bloomsbury Publishing.

Bexley, E., Arkoudis, S., \& James, R. (2013). The motivations, values and future plans of Australian academics. Higher Education, 65(3), 385-400. https://doi.org/10.1007/s10734-012-9550-3

Burke, P. J. (2008). Writing, power and voice: Access to and participation in higher education. Changing English, 15(2), 199-210. https://doi.org/10.1080/13586840802052419

Burke, P. J. (2012). The right to higher education: Beyond widening participation. foundations and futures of education. Routledge, Taylor \& Francis Group.

Devos, A. (2003). Academic standards, internationalisation, and the discursive construction of "the international student." Higher Education Research \& Development, 22(2), 155-166. https://doi. org/10.1080/07294360304107

Gagnon, J. D. (2018). 'Bastard' daughters in the ivory tower: Illegitimacy and the higher education experiences of the daughters of single mothers in the UK. Teaching in Higher Education. https://doi. org/10.1080/13562517.2018.1449743

Gair, S., \& Baglow, L. (2018). Social justice in a tertiary education context: Do we practice what we preach? Education, Citizenship and Social Justice, 13(3), 207-216.

Hall, M. (2012). Inequality and higher education: Marketplace or social justice? Leadership Foundation for Higher Education.

Hamshire, C., Forsyth, R., Bell, A., Benton, M., Kelly-Laubscher, R., Paxton, M., et al. (2017). The potential of student narratives to enhance quality in higher education. Quality in Higher Education, 23(1), 50-64. https://doi.org/10.1080/13538322.2017.1294407

Hamshire, C., Forsyth, R., \& Player, C. (2018). Transitions of first generation students to higher education in the UK. In A. Bell \& L. J. Santamaria (Eds.), Understanding experiences of first generation university students: Culturally responsive methodologies (pp. 121-142). Bloomsbury.

Hamshire, C., Willgoss, T. G., \& Wibberley, C. (2012). 'The placement was probably the tipping point'The narratives of recently discontinued students. Nurse Education in Practice, 12(4), 182-186.

Hamshire, C., Willgoss, T. G., \& Wibberley, C. (2013). Should I stay or should I go? A study exploring why healthcare students consider leaving their programme. Nurse Education Today, 33(8), 889-895.

Jawitz, J. (2016). Unearthing white academics' experience of teaching in higher education in South Africa. Teaching in Higher Education. https://doi.org/10.1080/13562517.2016.1198760

Jehangir, R. (2010). Higher education and first-generation students: Cultivating community, voice, and place for the new majority. Springer.

Kahu, E. R., \& Nelson, K. (2018). Student engagement in the educational interface: understanding the mechanisms of student success. Higher Education Research \& Development, 37(1), 58-71. https:// doi.org/10.1080/07294360.2017.1344197

Laubscher-Kelly, R., Paxton, M., \& Majombozi, Z. (2018). \#FIFUMustRise: Factors affecting the success of students who are first in the family at a South African University. In A. Bell \& L. J. Santamaria (Eds.), Understanding experiences of first generation university students: culturally responsive methodologies (pp. 97-120). Bloomsbury. 
Leach, L. (2011). 'I treat all students as equal': further and higher education teachers' responses to diversity. Journal of Further and Higher Education, 35(2), 247-263. https://doi.org/10.1080/03098 $77 \mathrm{X} .2010 .548858$

Leathwood, C., \& O'Connell, P. (2003). 'It's a struggle': The construction of the 'new student' in higher education. Journal of Education Policy, 18(6), 597-615. https://doi.org/10.1080/026809303200014 5863

Mbembe, A. J. (2016). Decolonizing the university: New directions. Arts and Humanities in Higher Education, 15(1), 29-45. https://doi.org/10.1177/1474022215618513

Milburn, A. (2012). University challenge: How higher education can advance social mobility. London.

Morrow, W. E. (2009). Bounds of democracy: Epistemological access in higher education. HSRC Press Cape Town.

National Planning Commission. (2012). National development plan 2030: Our future - make it work. National Planning Commission.

O'Shea, S., \& Delahunty, J. (2018). Getting through the day and still having a smile on my face! How do students define success in the university learning environment? Higher Education Research \& Development, 37(5), 1062-1075. https://doi.org/10.1080/07294360.2018.1463973

O'Shea, S., Lysaght, P., Roberts, J., \& Harwood, V. (2016). Shifting the blame in higher education social inclusion and deficit discourses. Higher Education Research \& Development, 35(2), 322336. https://doi.org/10.1080/07294360.2015.1087388

O’Shea, S., May, J., Stone, C., \& Delahunty, J. (2017). First-in-family students, university experience and family life: Motivations, transitions and participation. Springer.

O'Shea, S. (2015). Filling up silences-first in family students, capital and university talk in the home. International Journal of Lifelong Education, 34(2), 139-155. https://doi.org/10.1080/02601 370.2014 .980342

O'Shea, S. (2016). Avoiding the manufacture of 'sameness': first-in-family students, cultural capital and the higher education environment. Higher Education, 72(1), 59-78. https://doi.org/10.1007/ s10734-015-9938-y

OECD. (2018). Education at a glance 2018: OECD indicators. OECD publishing.

Pascarella, E. T., Pierson, C. T., Wolniak, G. C., \& Terenzini, P. T. (2004). First-generation college students: Additional evidence on college experiences and outcomes. The Journal of Higher Education, 75(3), 249-284.

Picton, C., Kahu, E. R., \& Nelson, K. (2018). 'Hardworking, determined and happy': First-year students' understanding and experience of success. Higher Education Research \& Development, 37(6), 1260-1273. https://doi.org/10.1080/07294360.2018.1478803

Reay, D., Crozier, G., \& Clayton, J. (2010). 'Fitting in' or 'standing out': Working-class students in UK higher education. British Educational Research Journal, 36(1), 107-124. https://doi. org/10.1080/01411920902878925

Ritchie, J., \& Spencer, L. (2002). Qualitative data analysis for applied policy research. The Qualitative Researcher's Companion, 573(2002), 305-329.

Sanders-McDonagh, E., \& Davis, C. (2018). Resisting neoliberal policies in UK higher education: Exploring the impact of critical pedagogies on non-traditional students in a post-1992 university. Education, Citizenship and Social Justice, 13(3), 217-228.

Smit, R. (2012). Towards a clearer understanding of student disadvantage in higher education: problematising deficit thinking. Higher Education Research and Development, 31(3), 369-380. https ://doi.org/10.1080/07294360.2011.634383

Spencer, L., Ritchie, J., Ormston, R., O’Connor, W., \& Barnard, M. (2013). Analysis: principles and processes. In J. Ritchie, J. Lewis, C. M. Nicholls, \& R. Ormston (Eds.), Qualitative research practice: A guide for social science students and researchers (2nd ed.). London: Sage.

Spiegler, T., \& Bednarek, A. (2013). First-generation students: What we ask, what we know and what it means: An international review of the state of research. International Studies in Sociology of Education, 23(4), 318-337. https://doi.org/10.1080/09620214.2013.815441

Srivastava, A., \& Thomson, S. B. (2009). Framework analysis: A qualitative methodology for applied policy research.

Tanner, K., \& Allen, D. (2007). Cultural competence in the college biology classroom. CBE-Life Sciences Education, 6(4), 251-258.

Thomas, L. (2012). Building student engagement and belonging in Higher Education at a time of change. HEA. 
Tinto, V. (2006). Research and practice of student retention: What next? Journal of College Student Retention: Research, Theory \& Practice, 8(1), 1-19.

Publisher's Note Springer Nature remains neutral with regard to jurisdictional claims in published maps and institutional affiliations.

Dr. Rachel Forsyth is Head of the University Teaching Academy at Manchester Metropolitan University and is a Principal Fellow of the Higher Education Academy. Her research interests centre on widening participation, curriculum design and assessment management. She is Editor-in-Chief of the Student Experience in Higher Education Journal.

Claire Hamshire is a Professor of Higher Education and the Head of Education forthe Faculty of Health, Psychology and Social Care at Manchester Metropolitan University,UK; combining a faculty role with a cross-institutional contribution to pedagogical research.She is also a UK HEA National Teaching Fellow, HEA Principal Fellow and the Vice-Presidentfor the European Region of the International Society for the Scholarship of Teaching andLearning (ISSOTL). Her research interests include first- generation students' experiences,peer-assisted learning, student engagement and learning transitions and she has publishedand presented research about students' learning experiences for the last decade.

Dr. Danny Fontaine-Rainen is the Director of the First Year Experience (FYE) Project, within the Center for Higher Education Development at the University of Cape Town (UCT). The. FYE is a campus- wide initiative designed to help first-year students make a successful transition into university and to develop a strong sense of belonging at UCT.

Leza Soldaat is a Lecturer of Social Science at Boston City Campus. Her educational background is in secondary school teaching and learning; and teacher's self-efficacy in this setting. Her research interests are an array of areas which include Higher Education culture, pedagogy, policy, and Minority studies. She works in an HE setting with a focus on racial/ethnic and gender integration at historically white institutions in South Africa.

\section{Authors and Affiliations}

\section{Rachel Forsyth $^{1}\left[\right.$ (D) Claire Hamshire $^{1} \cdot$ Danny Fontaine-Rainen ${ }^{2} \cdot$ Leza Soldaat $^{3}$}

Claire Hamshire

c.hamshire@mmu.ac.uk

Danny Fontaine-Rainen

danny.fontaine@uct.ac.za

Leza Soldaat

Leza.Soldaat@uct.ac.za

1 Manchester Metropolitan University, Manchester, UK

2 University of Cape Town, Cape Town, South Africa

3 Boston City Campus and Business College, Emalahleni, South Africa 